Guest Editorial, part of a Special Feature on Public policies and management of rural forests: lasting alliance or fool's dialogue?

\title{
Public Policies and Management of Rural Forests: Lasting Alliance or Fool's Dialogue?
}

\author{
$\underline{\text { Genevieve Michon }}^{1}$, Robert Nasi $^{2}{ }^{\text {and }}$ Gérard Balent $^{3}$
}

\begin{abstract}
Most people in forest and rural areas manage trees as part of their livelihood systems. The resulting "domestic" or "rural" forests are distinct from conventional forest. They have historically been overlooked by the forestry sector and impacted by forest policies and regulatory frameworks. These forests presently encounter requalification and valuation dynamics, fueled by a sustainable development ideology, and induced by both public powers and local communities. These dynamics move in two different directions: the naturalization of rural forests by policy makers, and their politization by rural people. We draw on long-term research experiences in France, Morocco, Southeast Asia, and Africa on forests managed by "farmers", among which some are analyzed in the Ecology and Society Feature, Public policies and management of rural forests: lasting alliance or fool's dialogue?. We first elaborate on domestication, analyzed at tree, ecosystems and landscape levels, as a concept allowing for a better understanding of the specific relationships developed between rural people and forests. We then engage in a critical review of how forest-related and sustainable development policies consider rural forests, and discuss how they address (or do not address) their specificity and encourage (or do not encourage) their development.
\end{abstract}

Key Words: domestication; forestry regulations; local forest management; patrimony; political ecology; public policies; resilience

\section{INTRODUCTION}

All over the planet and throughout history, people have been managing trees as part of their agricultural activities and livelihoods. This is obvious in Europe where rural landscapes integrate various forest patches: small woodlots intertwined with fields, isolated trees in pastures and linear forests bordering grass fields (Balent 1996, Baudry and Jouin 2003). This is less conspicuous in areas with relatively continuous forest landscapes, such as in tropical forests, Mediterranean bushland, or wooded savannas and steppes in Africa, where it is easier to deny the positive role of local farmers in shaping the forest ecosystem (Balée 1998, Fairhead and Leach 1996, Simenel 2011) (Fig. 1 and 2).

The resulting "rural forests" appear as somewhat distinct from conventional forests; they exhibit common characteristics from North to South, though are rather contrasted as far as tree species, ecosystem structure, management practices or underlying institutions are concerned (Génin et al. 2013). The major distinction is that they are the product of planned farming and are attached to the domestic economies in the surrounding areas. But because they are forests, they are still often impacted at a national scale by forest policies and regulatory frameworks. These policies and associated forest management regimes are devised to manage forest domains in the name of the State but are not meant to incorporate the interests and logics of rural forests. They have therefore contributed to the concealment of the realities of rural forest management, led to global misinterpretation of its importance and characteristics, and impeded its development.
Fig. 1. Rural forests: Argan forest in Morocco (above), chestnut forest in Corsica (middle), farmers' forest in France (below)
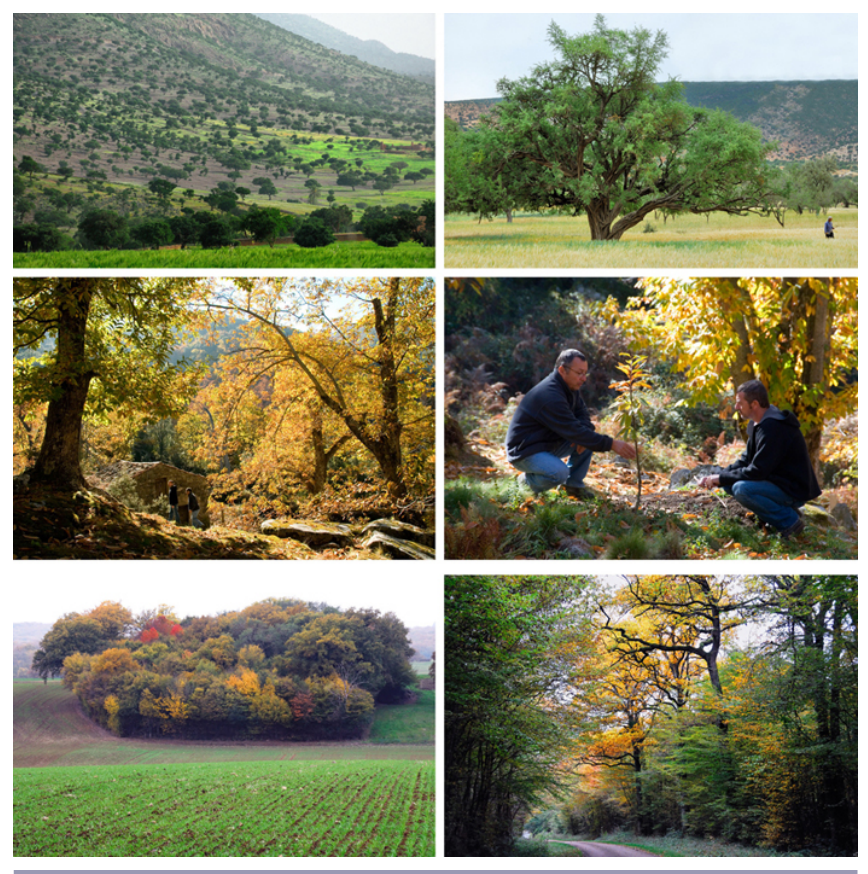
Fig. 2. Rural forests: Agroforests in Indonesia (above) with damar (Shorea javanica) (left) and rubber (Hevea brasiliensis) (right), Agroforests in India with coffee (below)
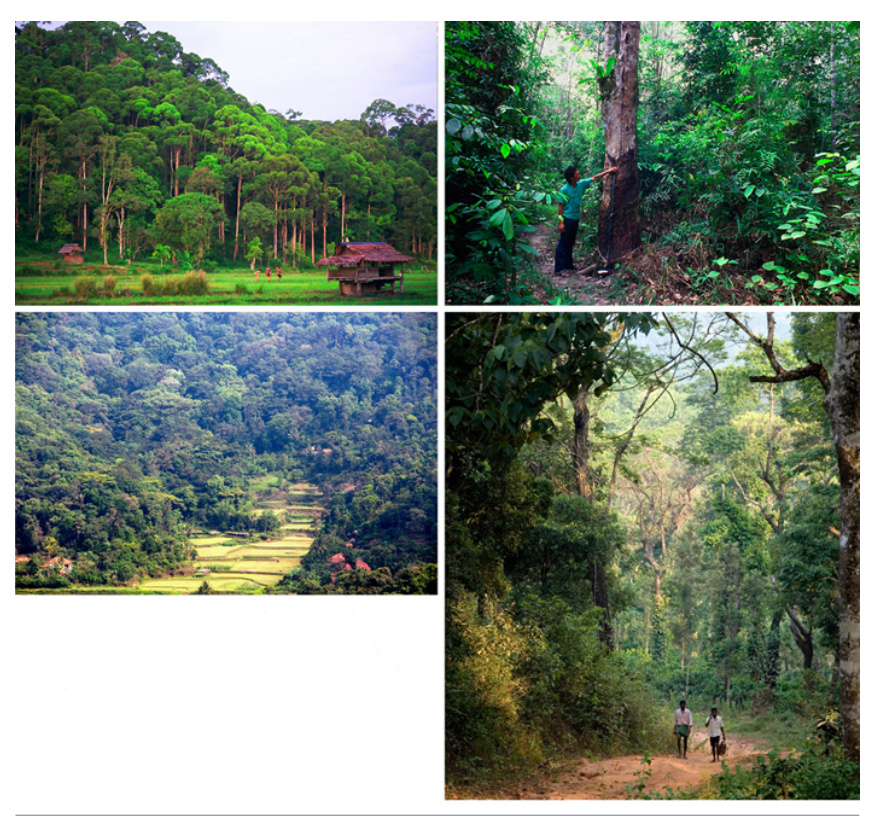

Precisely because of (or despite) that, rural forests constitute highly resilient social-ecological systems. For centuries, rural forests have resisted national forestry frameworks that have tried to limit local forest-related practices and expel farmers from the forest. Rural forests have survived agricultural intensification and modernization that have attempted to eliminate trees from agricultural landscapes in order to rationalize local production patterns. Today, in many places in the world, outmigration from rural areas and related transformation of rural lands favor their extension or rejuvenation. These forests therefore constitute a good entry point for understanding the role public policies play in the resilience of social-ecological systems and how they may encourage or discourage a path towards sustainability.

The failure of capitalistic agriculture and the global economic crisis put rural forests back in the heart of economic strategies in many rural areas, through various valuation processes supported by a sustainable development ideology. Some of these processes are locally born and carried out by local actors: territorial qualification of forest products (chestnuts in southern Europe, pork meat from the dehesa forests in Spain) and the revival of abandoned forest productions (black truffles in southern France). Others are designed through a top-down approach: support of "community forests" (Cameroon) or "tribal forests" (India) and product certification (argan oil in Morocco) (Fig. 3). Does this then illustrate a reversal of historical trends and a turn towards a future where these forests would acquire legitimacy and be integrated in a renewed rural development?

Drawing on long-term research experiences in France, Morocco, Southeast Asia, and Africa on forests managed by "farmers" (shifting cultivators, settled farmers, and/or seminomadic shepherds), and following authors in these specific fields, we elaborate on concepts for a better understanding of the specific relationships that have evolved between rural people and forests, ecosystems and landscapes. We then engage in a critical review of how forest-related and sustainable development policies consider forests, in general, and discuss how they address (or do not address) the specificity of rural forests and encourage (or do not encourage) their development.

Fig. 3. Sustainable development initiatives in rural forests: Geographical Indication for rural forest products (pork meat in the Spanish dehesa: above left, chestnut flour in Corsica: above right, argan oil in Morocco: below right) or Community Forestry in Cameroon (below left)

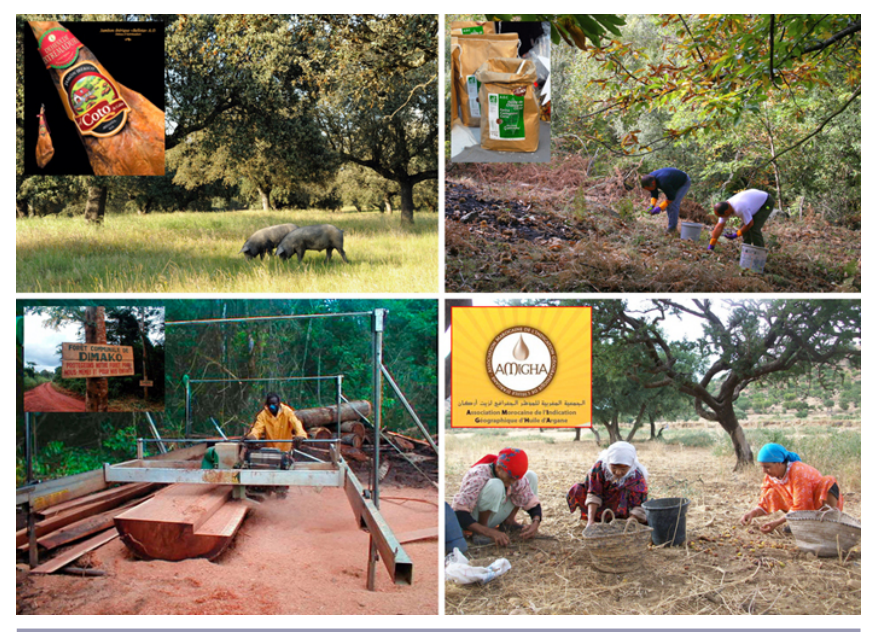

\section{RURAL LANDSCAPES: DOMESTICATING THE ORIGINAL FOREST?}

Rural forests are not typically managed from a professional forestry perspective. Their existence relies on specific practices and their design incorporates strong livelihood and social dimensions (Sauget 1994, Wiersum 1997). They have evolved from long-standing and complex domestication processes targeting trees, ecosystems and landscapes (Michon et al. 2007).

\section{Domesticating trees}

Practices on trees range from light manipulations (favoring selected individuals in untouched forests and selectively weeding around them) to strong interventions (planting, pruning, breeding, grafting). 
At the far end of this spectrum, domestication is obvious. In southern Europe, chestnut trees (Castanea sativa) are the "most humanized of all European forest trees" (Michon 2011) and have been domesticated since the Middle Ages. The domestication process has followed a classical development pattern: selection in the wild, plantation, selection of the most desirable individuals in cultivated stands and finally, reproduction of the selected varieties by grafting. Today, one single village in a chestnut-producing area may hold dozens of local varieties.

But for most tree species in rural forests, domestication remains more or less invisible, like for the holm-oak of dehesas (Linares 2007), or néré (Parkia biglobosa) and karité (Vitellaria paradoxa) in African parklands (Boffa 1999). The argan tree (Argania spinosa) in southern Morocco is also considered "wild". The high variety of shapes and architecture, from large trees in fields to tortured individuals which goats climb for foraging, or rock-like shrubs in heavily grazed areas, is generally attributed to the combination of natural conditions and tree responses to grazing (Fig. 4). However, detailed research (Génin and Simenel 2011, Simenel 2011) has shown that local people intentionally design trees in this way. The production of umbrella-shaped trees in barley fields requires careful and continuous pruning in order to produce a single stem with a large canopy that prevents low branching. In rangelands, trees are tailored through selective pruning or branch curving, which either facilitates goat foraging (fostering horizontal branches) or prevents it (favoring vertical branches). Argan trees are not planted, but in addition to protecting and fostering natural seedlings in fields, farmers also practice cultivation of stem and root suckers in order to regenerate stands. Pruning, shaping and intertwining suckers also helps or constituting dense living edges that prevents goats from entering barley fields. Overgrazed trees are not locally considered to be degraded, as they can revert to a tree shape as soon as the grazing pressure is relieved.

Tree domestication in rural forests constitutes an original strategy compared to tree domestication in horticulture or conventional forestry, as:

- It does not focus on the selection of single-purpose genotypes but targets both increased production and the maintenance of a high level of genetic diversity.

- Given tree species (argan, oak, juniper, ash) can be managed in diverse ways depending on the desired function or resources enhanced.

- It incorporates a certain degree of fluidity between wild and domesticated, as exemplified in the chestnut example, where domesticated trees still look like large forest trees and where trees reproduced from natural seedlings are considered "wild" (bastardu), even though the seeds come from varieties that have been selected for centuries. This wild component is linked to tree reproduction as bastardu are considered the best pollen producers, and therefore the strongest reproducers and the best stocks for grafting (Michon 2011).

- It relates the tree to the human sphere through the immaterial practices of domestication. In chestnut orchards as well as in the argan forest, venerable trees are given names, and family or village histories are linked to them (Dupré 2002, Simenel 2011). In that respect, they enter the domestic circle of village families and are the representations of their collective memory. Such diversity, induced by selection practices at the tree level, is locally highly valued. In chestnut areas, villages' identity and pride are related to the array of their chestnut varieties that contribute to the specific flavor of the chestnut flour (Michon 2011). Argan farmers classify and name eight tree categories related to the tree's size and architecture. They also use a highly refined terminology that defines the type and quality of fruits and "provides indices of a long term domestication process" (Génin and Simenel 2011).

Fig. 4. Domesticating the argan tree: Umbrella-shape for argan trees in fields (above left), Several stems in collective rangelands (above right), forage tree in family rangelands (middle left) with stone "stairs" (middle right), hedges in villages and fields (below left), "Green-Rock" in collective rangelands (below right)

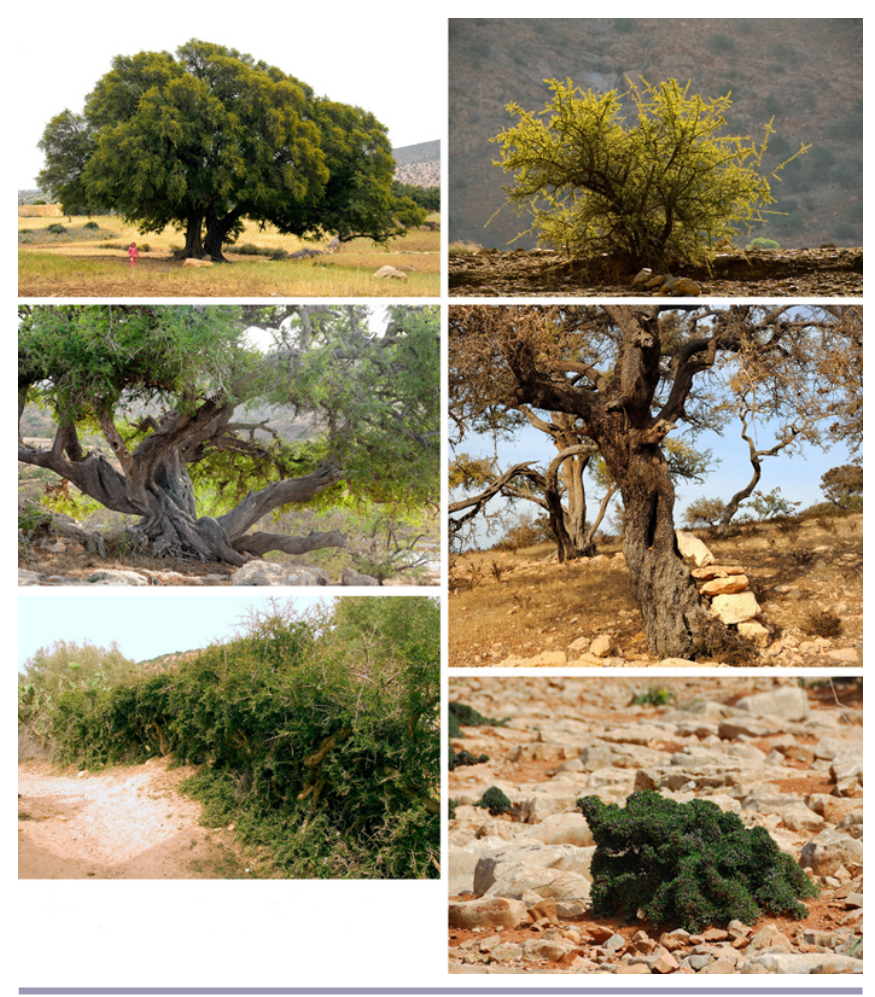




\section{Domesticating the ecosystem}

Domestication in rural forests also relies on specific processes targeting ecosystem design. This remarkable strategy of ecosystem domestication means it retains the complexity of its natural structures, making full profit of natural vegetation dynamics while retaining the original ecosystem's qualities, including the basic principles of natural silvigenetic succession and of forest production (Michon et al. 2007).

Agroforests in Indonesia are the best example of ecosystem domestication. They "originate from the (partial or total) slashing and burning of original forests with the planting of trees in the swiddens. They evolve through gradual forest reconstruction involving plantation, protection, selection and facilitation of natural regeneration processes. Once developed, these planted forests reproduce themselves without disruption in structural or functional patterns over the long run with minimal input, thanks to a balanced combination of anticipated replacement of decaying individuals, mimetic gap planting, and respect of natural dynamics. These practices allow further diversification through the colonization by many forest species inside the cultivated stand" (Michon et al. 2008) (Fig. 5). The resulting agroforest looks like a natural forest ecosystem, with "a high canopy, dense undergrowth, high levels of biodiversity, and a perennial structure", and produces without significant human interference.

Fig. 5. Fostered silvigenetic development processes in the establishment of Benzoin Agroforest in North Sumatra, Indonesia: farmers introduce benzoin seedlings in the cleared undergrowth of old-growth forest, let it grow with self-established species, then clear the agroforest for regular harvesting for 40 to 60 years, and let the ageing agroforest revert to an old-growth forest for a new planting cycle

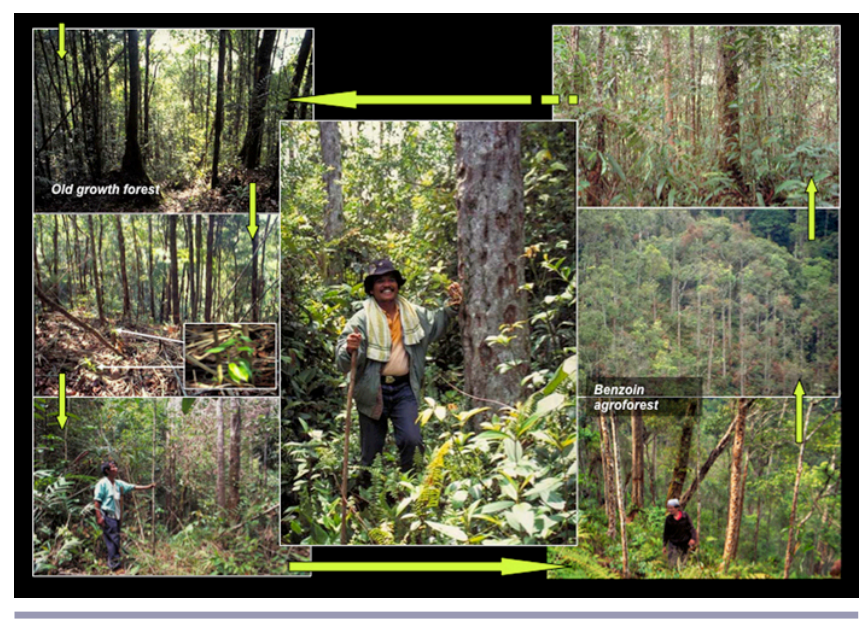

Another significant example of forest ecosystem domestication is the high level of both genetic and specific diversity of oaks in the fragmented forests of French Gascony, resulting from multifunctional forest management practices by local people (Lepais et al. 2006). The coexistence in small rural forest patches of four oak species (Quercus robur, $Q$. petraea, $Q$. pubescens, and $Q$. pyrenaica), differing in their growth capacity, their temperature and rainfall tolerance, results in forest habitats with a high level of biodiversity (Monteil et al. 2005) and increases the resilience of these rural forests in response to ongoing climatic changes (Fig. 6).

Fig. 6. Farmers' forests in French Gascogne: a fragmented forest-type in agricultural lands managed for firewood production, game hunting and mushroom collection, with high levels of biodiversity

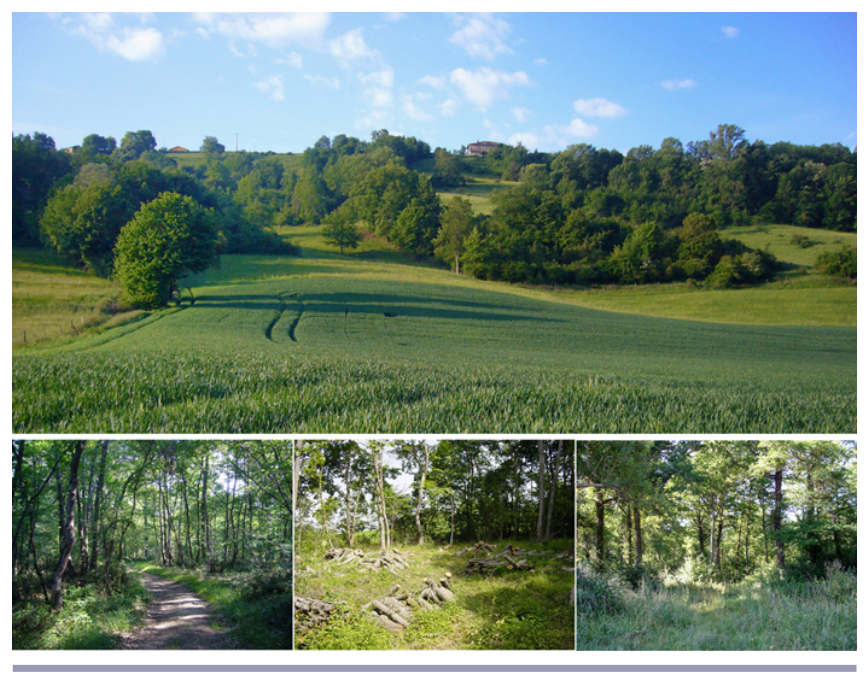

The main characteristic of ecosystem domestication lies in the fluidity between what relates to human practices and what relates to nature. Contrary to the ecological oversimplification and strong control associated with modern agriculture or even tree culture and orchards, management practices foster desired productions while containing wilderness within acceptable limits. Michon (2011), for example, shows that the chestnut orchard exhibits a rather continuous back and forth movement between wild, managed and cultivated with a coevolution of practices and ecosystem structure. Management intensification fosters the establishment of chestnut stands, while reverting to wilderness allows the system to survive abandonment. Today, chestnut producers try to devise a new compromise between wild and domestic. Aumeeruddy-Thomas et al. (2012) show a similar process of balancing nature and culture in reinvesting in garrigues for truffle production in southern France.

\section{Domestication at the landscape level}

On a larger scale, as noted by Erickson (2006), forest farmers would invest more energy in "domesticating landscapes as a whole than in domesticating individual species of plants and animals." At this level, domestication develops through several strategies, including: 
- Development of specific infrastructures linked to forest culture and production: irrigation channels, terraces or small walls aimed at soil and water conservation in the argan forest and in sloping chestnut areas, barns attached to ash tree farms in the Pyrenees, buildings for chestnut storing, drying, and molding.

- Functional specialization through spatial distribution of practices and rights creating differential forest types in the landscape, especially in botanically rather homogeneous forests. The chestnut forest is divided into: orchards intensively managed for fruit production; foraging spaces devoted to pork production and very extensively managed; and chestnut groves devoted to timber production, managed through coppicing. The argan landscape is compartmentalized into different types of stands corresponding to different levels of argan tree exploitation: agroforestry areas, with large argan trees scattered in the middle of individually-owned cultivated fields; agdal devoted to foraging and nut harvesting managed and owned by family branches; foresters' agdal under the jurisdiction of the State, where foraging is allowed but where forest management (timber harvesting and rejuvenation through coppicing) dominates; and collective foraging areas with overgrazed trees which act as a buffer to release pressure on other compartments (Génin and Simenel 2011).

- Distribution between open fields, forest plots and individual trees, which creates highly varied patterns, from rather continuous forest cover (the argan forests or the Indonesian agroforests) to forest islands scattered over an agricultural landscape (the small peasant forest in south-western France (Sourdril et al. 2012), forest agdal in the High Atlas, (Auclair et al. 2011) or agricultural landscapes compartmentalized by trees and linear forests (Baudry and Jouin 2003) (Fig. 7).

Some rural forests have helped develop true cultural landscapes: the chestnut forest in Corsica (Michon 2011) and in the Cevennes (Dupré 2005, Aumeeruddy-Thomas et al. 2012). These cultural landscapes provide a specific economy that sustained the highest population densities in Europe at the turn of the 20th century. Others include the argan forest, which covers around 900,000 ha and sustains 2.5 million people (Nouaïm 2005), the dehesa system in Spain (San Miguel 1994), or the damar agroforest in the south of Sumatra (Michon and de Foresta 1999).

As developed elsewhere, forest domestication also includes a strong immaterial component that relates a particular forest (and its components, from trees to landscapes) to a human group, its history and its domestic units (Michon et al. 2007).
Fig. 7. Landscape domestication patterns in rural forest systems: from continuous forest cover (above) in the damar agroforest in Indonesia (left) and in the argan forest in southwestern Morocco (right) to forest fragments (forest "agdal" in the Moroccan High Atlas: below, left, and linear forests and woodlots in Central France: below right)

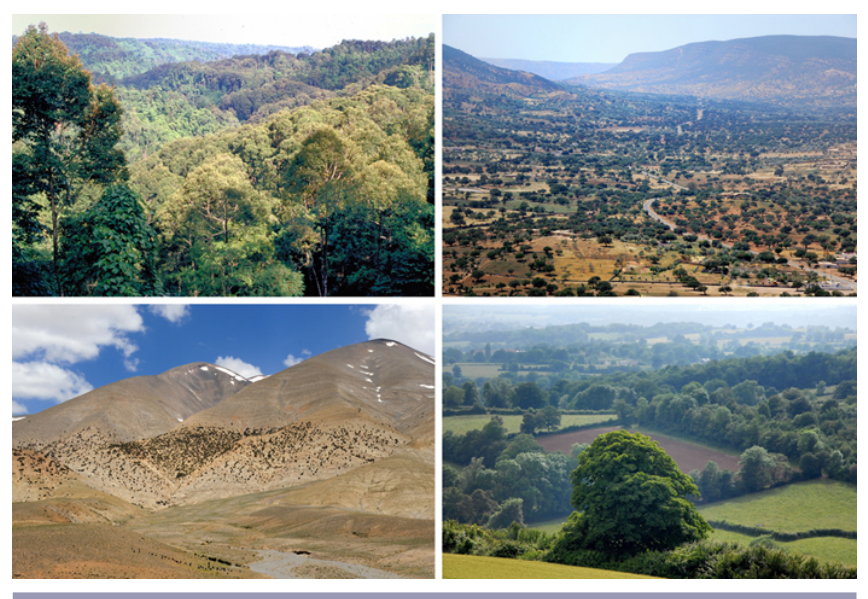

\section{THE POLICY LANDSCAPE: RECONCILIATION BETWEEN FOREST AND AGRICULTURE?}

Rural communities managing forests usually do not differentiate between what is forest and what is agriculture. But their forests are subjected to public policies and related technical support services that usually draw a distinct line between agriculture and forestry, which do not take into account local forests' specificities.

\section{Competing visions of the forest}

From the international level to nations and regions; from historical times to the present; forest visions and policies incorporated two main categories of elements.

The first category refers to public goods and interests, which nowadays globally relates to environmental concerns: fauna, soil or watershed preservation, biodiversity conservation, ecosystem services and climate change mitigation. This reflects a vision of a "moral forest" that relies on principles, theories and management norms deemed to be universal: forests stand at the center of the planet's equilibrium and have to be managed in order to preserve global environmental processes as well as the future of humankind (Kouplevatskaya and Buttoud 2008). This "environmental forest" is globally considered as uninhabited, except for some emblematic populations holding a unique and irreplaceable traditional ecological wisdom. Farmers are deemed to be forest enemies whose practices (slash and burn agriculture, nomadic herd foraging, hunting, and harvesting) contribute to the destruction of the ecosystem and its wealth. This vision is mediated by 
international institutions and NGOs and incorporated in national forestry frameworks.

The second forest vision refers to nations' interests and focuses on forest valuation, mainly through wood production (timber, fuelwood). This vision has led to the constitution of forests as specific legal entities: state forest domains managed through (1) a system of rules and regulations concerning forest access, use and control, (2) harmonized silvicultural practices, (3) for the production of benefits derived from wood exploitation (Fay and Michon 2005). The development of scientific forestry established professional foresters as the only knowledgeable and legitimate forest managers, thus discarding farmers and local people. This has entailed important biases for rural forests management, as noted in the papers by Lescuyer et al. (2012) in Cameroon, and Rives et al. (2012) in Niger.

A third vision has been emerging over the last two decades or so, mainly in Europe: the recreational forest. This forest is tailored by and for urban dwellers, and, again, managed by foresters and national or local public services.

None of these visions accommodate rural forests' logics nor integrate their social, productive and environmental functions. From a farmer's point of view, forest is much more than merely timber, fuelwood or biodiversity, and forest management is carried out mainly for sustaining local livelihood—even if this management also incorporates concerns for more global interest. These diverging views on forests, and the policies they inspired, fuelled centuries of conflicts between farmers and forest managers and inspired the definition and enforcement of strict normative and prescriptive frameworks incorporating high levels of state intervention, legitimized by environmental and production interests. The consequences of these linger even now, as reported in several papers in a special issue: for India (Macura et al. 2011), Morocco (Auclair et al. 2011), and Niger (Rives et al. 2012).

\section{Local forest in agrarian frameworks}

Agrarian frameworks and agricultural policies are regulating either through market mechanisms or by systems of incentives/ disincentives. In theory, as they are not directly compulsory and give freedom of choice to practitioners, they should offer better opportunities for the incorporation of rural forests' logics and interests. But they fail to do so. Conventional agriculture not only ignores rural trees and forests, but also considers them as an impediment to agricultural production. Ignoring the articulation between forest and agriculture, and the continuity of farmers' practices from forests to fields and pastures, has prevented farmers from engaging in planting trees. In France, until recently, when farmers wanted to incorporate trees in their fields, they could not claim national subsidies; chestnut managers could not be registered as farmers (Michon 2011); the role of Mediterranean bush for grazing is still denied and farmers have to hold grass fields to be registered as farmers. The Indian and Indonesian laws still differentiate between "forest trees" and "agricultural trees", the former belonging to the State even if they grow on farmers' fields (Menon et al. 2009).

This segregation has caused, for example, the disappearance of Sandalwood trees in West Timor in Indonesia. The sandalwood dispute was so sensitive that foresters used to patrol local farms to control the presence and integrity of sandalwood trees. Farmers were so harassed that they preferred to uproot sandalwood seedlings from their fields (Michon 2005). In the Western Ghats of India, farmers have, over time, replaced the "forest trees" that shade the coffee plantations on their farms, with fruit trees and fast growing species (Menon et al. 2009), resulting in a significant decrease in forest biodiversity in the region. At worst, this segregation means that farmers are deprived of much of their land resource base (Fay and Michon 2005). This also happens in the extension of plantation agriculture in Indonesia, where large estates are given preference and local farmers are hired as wage laborers.

\section{Do sustainable development policies help?}

Sustainable development policies should offer better opportunities for the recognition and development of rural forests, particularly through such mechanisms as enhancing biocultural products or the promotion of shared governance systems.

Studies show that implementation of such policies often fails in enhancing local development dynamics: projects barely meet local people's expectations and communities' participation remain very low when defining projects' objectives and development. This gap comes from a global misunderstanding: developers (who are often trained in forestry or agriculture) fail to understand the complexity of local social-ecological functions linked to rural forests (Rives et al. 2012), whereas communities are reluctant to endorse the rationale and objectives of sustainable development as it is offered to them (Macura et al. 2012).

There seems to be three main causes for this problem.

The first cause relates to the slow rate of change in classical representations of what is a forest and of farmers' attitudes towards trees and forests (Boutefeu and Arnould 2006). Most foresters are still convinced that they have to teach local people how to sustainably manage a forest and are reluctant to share knowledge and control over forest resources with local communities (Macura et al. 2012).

The second cause comes from the fact that many forest-related projects tack "sustainable development" onto conventional forest development models, thus reducing the sustainable development concepts to more classical norms. "Participation" thus becomes "inviting local people" into an already defined plan (Auclair et al. 2011, Lescuyer et al. 2012) in which their 
power is quite limited. "Dialogue" is restricted to information meetings (Macura et al. 2012), and "social forestry is often targeted at degraded zones of the reserved forests with the aim of restoring them with the participation of the people" (Macura et al. 2012). "Multifunctionality" is narrowed to one aspect of forest production (Rives et al. 2012, Kouplevatskaya and Buttoud 2008) or to preparing the forest for recreation (France). Sustainable production more than often means sustainable production of wood. Rural forestry schemes focus globally on encouraging local people to access conventional forest management rather than adapting to rural forest management logic. Lescuyer et al. (2012) show that the integration of local use rights or local knowledge and practices into community forest management plans is primarily formal. Kouplevatskaya and Buttoud (2008) showed that in France, even if local forest policies target rural development and farmers' participation, forest management still focuses on classical forest services (provision of timber and energy, protection of "remarkable" plant or animal species) and not on the real farmers' needs and interests.

The third cause is more subtle and complex. Although efforts are made by forest services and governments to incorporate a new vision of rural forest communities and forestry, they fail in fully translating this new vision into action. As revealed by Rives et al. (2012) in Niger, decentralization released the state's monopoly over forest management and gave rights back to communities. However, sustainable forest management projects failed in questioning the representation of wood as the only function of local forests, as well as the only forest livelihood support.

These obstacles become more important when states try to involve local communities in sustainable forest management in a context of global failure of national forest development policies.

But there are signs of slow improvement: some examples show a process of mutual learning between the developers, forest agents, local NGOs and local people, though still diffuse and poorly formalized (see Lescuyer et al. 2012 for Cameroon, Garcia et al. 2010 for India, and Michon 2011 for Corsica). State administrations are processing sustainable development norms and plans in regards to the definition of rural and forest projects by incorporating and listening to local people, who are eager to demonstrate the sustainability of their forestrelated practices. Even if the necessary acknowledgement and incorporation of local practices into forest development is still in the early stages, the situation is evolving.

\section{The influence of market}

In this context of unsatisfactory public policies regarding rural forests, the market and its globalization represent substantial driving forces, either directly through free options for income generation offered to farmers, or indirectly through new forestrelated market instruments (conservation concessions, payment for environmental services, REDD mechanisms, etc.).

Some authors have shown that in forest areas in the south, rural development relies on macroeconomic factors, which promote the development of industrial agricultural commodities (coffee, cocoa, rubber, and oil palm) (Sunderlin et al. 2000, Wunder 2001). Feintrenie et al. (2010) report how the national and international economic contexts clearly influence Indonesian farmers' decisions about their forests, for example. In Sumatra, local famers opt for the removal of their agroforest and changes in their livelihood in the interest of increasing their income. In Cameroon, sustainable forest management policies do not provide sufficient income generation opportunities to local people compared to agricultural policies and macro-economic dynamics (Lescuyer et al. 2012). In Morocco, NGOs' and market-driven developments of argan oil for international consumption is slowly changing the familial nature of the argan forest, which could deprive the rural poor of their argan resources (Simenel et al. 2009). In most southern countries, agricultural development still relies on the elimination of trees and forests, whether on government lands or in rural forests.

On the contrary, in France, management of rural forests is driven by patrimonial rather than economic concerns. However, the development of the land market for recreational uses holds a high potential for dissociating rural forests from their social rural bases, as observed in the Corsican chestnut forest (Michon 2011), in farm-related forests of Gascogne (Sourdril et al. 2012) or in Pyrenean farms (Gibon et al. 2010).

Moreover, the sudden burst of market mechanisms and policies related to climate change is dramatically changing the forest landscape towards a direction in which concerns for biodiversity, local knowledge of sound governance are of secondary importance. Carbon storage gives foresters and environmentalists the first voice and restores their faded legitimacy. This tendency expresses itself in northern and southern forests: foresters in France reinvest in once "inactive" forests (Mediterranean bushes, naturally afforested plots, smallholder's private forests) for an intensified and rationalized fuelwood production, whereas forests in the south are nowadays driven by REDD mechanisms. How will rural and domestic forests survive this carbon steamroller?

\section{DISCUSSION: RURAL FORESTS, BETWEEN RESILIENCE AND POLITICAL ECOLOGY}

As a social-ecological system, rural forests link specific vegetation and human groups. The co-evolution of these two components is closely related to practices, rules and perceptions anchored in local livelihoods, history and culture, and the links between humans and trees. Also, there exists a complex interrelationship established between rural populations and other segments of societies (local to international). Resilience and sustainability rely on socio- 
environmental and biocultural integration at various scales: tree/uses and practices; ecosystem/knowledge and practices; landscape and local users/social and political environments.

\section{Resilience: the quality of socio-environmental and biocultural integration at various scales}

Rural forests have often been presented by foresters as "the end of the forest", but they present a set of qualities for resilience. At tree and ecosystem level, adaptive management, rather than the search for maximal control, is the rule to retaining economic and environmental quality. This adaptive approach concerns management practices and institutions, which continuously stick to changing biological, ecological, economic and political conditions (Génin et al. 2013). Our modern idea of land management operates through a process of segregation of production, conservation and cultural functions in distinct compartments of the landscape. Rural forests are based on a close integration of these functions in a single spatial unit. Because of the close connection between rural forests and other agricultural activities in livelihood systems, this integration reinforces the safety and the autonomy of both forest and agricultural systems. It can also be analyzed in terms of diversification as opposed to specialization. Diversification benefits balance levels of production for individual crops that remain lower than those observed through systems of monoculture or specialized management. The close connection of the rural forest management with agriculture is an essential quality. When the classical forest management is based on cycles rarely compatible with the needs and the necessary flexibility of the local production, the rural forest relies on the various complementary production cycles, which allows fulfilling altogether regular, annual and exceptional needs. Under its various avatars, the rural forest impacts directly the sustainability of both the production systems and the territories in which it is included.

As mentioned above, this socio-environmental and biocultural integration implies maintaining a complex balance between nature and culture, which seems to be the dominant factor in resilience. Balent (1996), Michon (2011), Michon et al. (2007), Sourdril et al. (2012), Aumeeruddy-Thomas et al. (2012), among others, show that rural forests, though sometimes highly modified compared to the original forest ecosystem, allows for the maintenance or restoration of forest economic, social and ecological functions in the agricultural landscapes. They also show that the fluidity between domestication and wilderness promotes rural forest's survival or development which maintains most of its originating functions, in a context of intensification (as reported for agroforests in Michon 2005) or disintensification (as reported for chestnut groves in Michon 2011 and Aumeeruddy-Thomas et al. 2012, or truffle culture in Aumeeruddy-Thomas et al. 2012). Rural forests constantly adapt to local needs and global conditions and evolve according to the evolution of requirements without necessarily or drastically changing their forest structures and functions. This "in-between" (between wild and domesticated, between nature and culture) relies on a continual and mutual adjustment between biological structures and dynamics on the one hand, and management practices and rules in the other. It constitutes a major factor in the capacity of rural forests to adapt to changing environments without losing their identity.

Some rural forests seem to be at a breaking point in their history and have to find new forms and functions to adapt. Some Indonesian agroforests succumbed to market forces and now these agroforests are being converted to monospecific cashcrop plantations. Feintrenie et al. (2010) report an important discontinuity in Indonesian agroforests: economic globalization that promotes the development of export-oriented national policies (based on agricultural commodities) pushes farmers towards increasing integration of cash crops in their economy. These cash crops consist of three main tree crops: cocoa, rubber, and oil palm. The authors mention that in order to cope with the price fluctuations of export commodities, farmers combine various cash crops on their farm. Instead of integrating them into their agroforest, they segregate the different crops into separate plots over the landscape. The authors conclude that this is the "end of agroforests". But this integration could also open up a new landscape - mixing trees and agriculture with segregated tree plantations and agroforests supported by international payments for environmental services. Gibon et al. (2010) show how the ashtree in the Pyrenees, which used to be a multifunctional resource in local rural forests (providing fodder, fuel, rack, fork, and collar), was strongly affected by the collapse of the traditional pastoral system and is seen today as an invasive species of grassland that fails to find its place in the modern mountain economy (Fig. 8). However, with the growing demands for alternative tree products, such as wood chips for domestic fuel or field fertilization, the ash tree could find a new role in the local economy and therefore find its place in a renovated rural forest landscape. Garcia et al. (2010) observed that in the Western Ghats in India, coffee agroforests are being converted to no-shade coffee plantations, but other authors reveal that the strongest move is towards a change in coffee landscapes from "forest trees" as a canopy of coffee gardens to the introduction of a fast growing species as either a light canopy for coffee or as a specialized culture.

\section{Rural forest and sustainable development policies: towards a political ecology}

As noted by Menon et al. (2009), "rural forests are often not autonomous local forests but the product of a complex relationship between the state and local actors mediated by public policies. And they often appear as sites of contestation between local actors and forest bureaucracies." 
Fig. 8. The evolution of ashtree-based rural forests in the Pyrenees, from traditional stands around the farm (above) to dense thickets colonizing abandoned pastures (below)

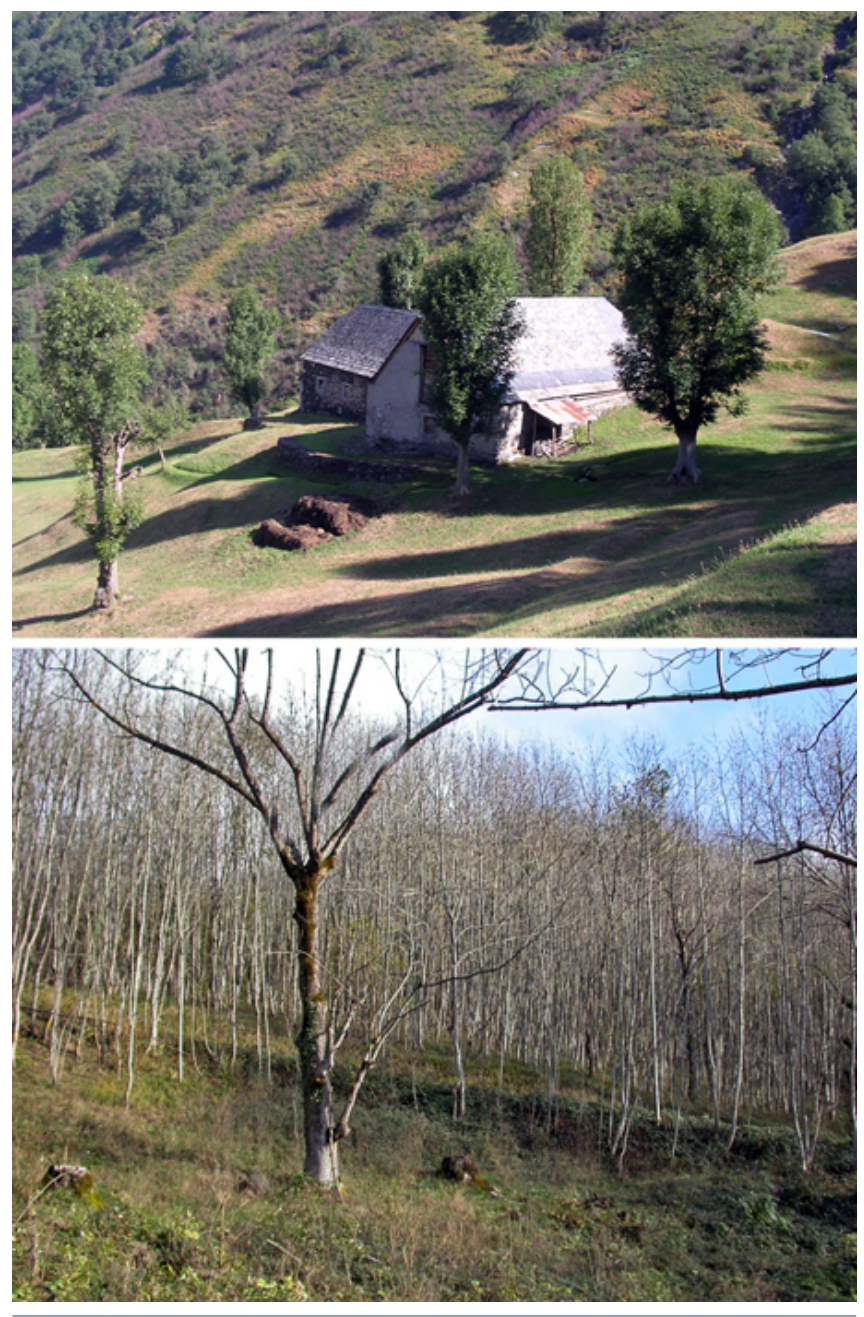

Rural forests result from a continuous management process occurring simultaneously at local, national and international levels, which has to be analyzed in light of local societies' dynamics and interactions with the political arena (particularly in the areas where the influence of the state on forest management is important). These interactions differ historically and from one country to another but definitively impact the resilience of both rural forests and the production systems in which they are included. They include elements of ideology (from foresters' point of view, the historical equating between rural forests and "backwardness" of rural populations; from a local perspective, the perception local forest as a symbol of resistance to a centralized state), actor's behavior (domination, imposition, resistance, incorporation, training, collaboration), rules and measures (repressive or inciting).
The analysis of these interactions shows a general mismatch between the management objectives in rural forests, and the objectives of public policies. The promotion of sustainable development norms and policies allows for a better acknowledgement of rural forests. However, dynamics induced by this requalification of rural forests by both public powers and local communities move in two different directions. These directions modify the relationships between these two categories of actors: the naturalization of rural forests by policy makers, and their politization by rural people themselves. These movements occur in the framework of opposing patrimonial movements, some being driven by states and international NGOs, others through bottom-up movements claiming for alternative rural development (Michon et al. 2012).

Political naturalization exists as a global tendency that expresses in different intensities all over the world. But everywhere, this global tendency takes the form of a progressive obliteration of the human traits in rural forests and the concentration on their environmental benefits. Rural forests are thus requalified through naturalist or environmental narratives that justify new development projects. Naturalization may reflect the reinforcement of sector-based logics like the community forests in Cameroon (Lescuyer 2005) or rural forests in India (Menon et al. 2009). It can come along with the "greening process" of agriculture, which tends to favor environmental services at large scales rather than production at local scales like in rehabilitation of chestnut forests in France (Michon 2011). It can accompany the environmental requalification of local knowledge into "traditional ecological knowledge", as observed in the international promotion of argan oil (Simenel et al. 2009) or the recognition of the value of Indonesian agroforests by the Department of Forestry (Fay et al. 2000). When political entities do not totally overlook the role of local people in the creation and management of rural forests, they present farmers as "managers of nature" and, consciously or not, tend to obliterate and even to prohibit some local practices considered as too agricultural, like slash-and-burn practices in Cameroon (Poissonnet and Lescuyer 2005). Or they ignore certain features that are obviously too domestic, like in the argan forest (Simenel et al. 2009). These political entities barely take into account the improvement of farmers' income and welfarewhich are key factors of farms' sustainability, particularly in forested areas with marginal economy. While being focused only on environmental aspects, these entities restrict the possibility of further development for forests, and contribute to denaturing the objectives of these policies developed in the name of sustainable development.

This political naturalization of rural forests echoes, in some cases, a real naturalization process of the forest through ecological dynamics linked to the abandonment or change in management practices: for example, shrub encroachment in 
the chestnut forests since the second half of the 20th century (Michon 2001); spontaneous afforestation in the garrigues of the Languedoc (Aumeeruddy-Thomas et al. 2012) or in the argan forest of the Moroccan Anti-Atlas (Simenel 2011); or ash tree invasion of abandoned pastures in the Pyrenees (Gibon et al. 2010).

The politization of rural forests is carried out by local actors themselves or their representatives (NGOs, associations). It is seldom presented as a political act. Rather, it develops as a process of social-ecological justification (as for Indonesian agroforests or tribal forests in India) or of economic valuation of forest products or landscapes, to which strong images of heritage, local knowledge or specific culture are attached. Politization opposes naturalization: rural forests are praised as socio-historical constructions. They are not a "forest" anymore, but the product of a long development history linking a social group, a geographical space and natural resources that have been completely redefined through specific knowledge and social rules.

Referring to patrimony, which highlights intergenerational transmission and solidarity, is constant (Michon et al. 2012). Patrimony refers either to lineage patrimony (private forest of Gascony: Sourdril et al. 2012; damar agroforests: Michon et al. 2000), or to collective patrimonies, as in the example of chestnut forests that are presented as the indivisible inheritance of Corsicans (Michon 2011). This patrimonial development aims at restoring or ensuring the persistence and the reproduction of elements (products, rules, know-how, etc.) considered as essential for the existence and the perpetuation of these social groups. It thus recovers strong identity claims (Corsica, Indonesia), often accompanied by land or political claims (India, Indonesia). In these patrimonial constructions, rural forests are put forward to legitimate actions that barely relate to sustainable development; however they address the sustainability of the rural forests through the definition or the stabilization of practices that prove to be ecologically sound, generate new income or allow for locally negotiated social coordination.

\section{CONCLUSION}

Rural forests constitute specific social-ecological systems that question long-established evidence (like the incompatibility between agriculture and forestry, long run and short term, nature and culture, wild and domesticated, or the presentation of production and services) as alternatively economic, environmental or social. In this sense, they allow refreshing analytic categories in the field of natural resources management. They also open original perspectives on relationships between agriculture and sustainable development and between public policies and local dynamics.

The current age of globalization (of ideas and products) and injunctions for sustainable development may represent a favorable context for further acknowledgement and development of rural forests.

A first move has already begun in scientific approaches. Foresters and biologists who have often seen the forest as an autonomous and natural system (away from the historical reality of societies who have used and transformed it) and have consistently considered humans as invaders and depredators, started considering humans as part of the forest ecosystem. Analyses move from impact studies to analyses of interaction and coconstruction. The approaches of specialists in ethnosciences, as well as conceptual frameworks of socialecological systems and of adaptive management, have helped considerably in analyzing the interactions between forests and local people in more positive terms, highlighting the project and investment dimension of local forest domestication. Further documenting and understanding rural forests of the world and accepting the various complementarities they exhibit could help repair the unproductive historical divide that has been established between forestry and agriculture.

As far as policies are concerned, sustainable development paradigm offer new perspectives for the development of these forests that do exhibit basic qualities for sustainability. Though rural forests are not biodiversity hotspots, highly productive forest systems, or a model for equitable sharing of rights and benefits, they do exhibit qualities in all these domains (Asbjornsen et al. 2004). Rural forests represent an important component of local economies that incorporate ecological and social bases. Imperatives for social justice and equity, the integration of governance and environmental values into production activities, and the common allegation that indigenous people are legitimate and experienced forest stewards, can bring new perspectives. In spite of the examples of local transformation and destruction, other examples of reinforcement of rural forests' legitimacy and profitability are multiplying. The ideology of sustainable development may allow these original forests to confirm their importance in areas that lie between biodiversity sanctuaries and intensive timber production areas.

Given sustainable development challenges in a context of financial crises and global changes, rural forests also represent an invaluable asset for marginal rural territories. It is important to allow them full expression of their potential. It is also important that they develop with the support of public policies, not against them. This, of course, requires an integrative, transdisciplinary and nonsector-based approach.

Responses to this article can be read online at: http://www.ecologyandsociety.org/issues/responses. php/5706 


\section{Acknowledgments:}

Part of this work was funded by the French Agency ANR within its ADD Program, under the POPULAR research program

\section{LITERATURE CITED}

Asbjornsen, H., A. Angelsen, B. Belcher, G. Michon, M. RuizPérez, and V. P. R. Wijesekara. 2004. Proceedings of the International Workshop 'Cultivating (in) Tropical Forests? The evolution and sustainability of systems of management between extractivism and plantations'. 28 June-1 July 2000, Lofoten, Norway. European Tropical Forest Research Network Publication Series, 86 pp.

Auclair, L., P. Baudot, D. Genin, B. Romagny, and R. Simenel. 2011. Patrimony for resilience: evidence from the forest Agdal in the Moroccan High Atlas Mountains. Ecology and Society 16(4): 24. http://dx.doi.org/10.5751/ES-04429-160424

Aumeeruddy-Thomas, Y., C. Therville, C. Lemarchand, A. Lauriac, and F. Richard. 2012. Resilience of sweet chestnut and truffle holm-oak rural forests in Languedoc-Roussillon, France: roles of social-ecological legacies, domestication, and innovations. Ecology and Society 17(2): 12. http://dx.doi. org/10.5751/ES-04750-170212

Balée, W. 1998. Advances in historical ecology. New York: Columbia University Press.

Balent, G. 1996. La Forêt paysanne dans l'espace rural: biodiversité, paysages, produits. Etudes \& Recherches sur les Systèmes Agraires et le Développement 29, 268 pp.

Baudry, J. and A. Jouin. 2003. De la haie aux bocages. Organisation, dynamique et gestion. INRA Edition, Paris, France.

Boffa, J. M. 1999. Agroforestry Parklands in Sub-Saharan Africa. FAO Conservation Guide 34, 230 pp.

Boutefeu, B. and P. Arnould. 2006. Le métier de forestier: entre rationalité et sensibilité. Revue Forestière Française 58: 61-72.

Dupré, L. 2002. Du marron à la châtaigne. La relance d'un produit régional. Éditions du Comité des Travaux Historiques et Scientifiques. Paris, France.

Erickson, C. L. 2006. The domesticated landscapes of the Bolivian Amazon. Pages 235-78 in W. Balée, and C. L. Erickson, editors. Time and Complexity in Historical Ecology: Studies in the Neotropical Lowlands. Columbia University Press, New York, U.S.A.

Fairhead, J. and M. Leach. 1996. Misreading the African Landscape: Society and Ecology in the Forest-Savanna Mosaic. Cambridge University Press, Cambridge, U. K. http:// dx.doi.org/10.1017/CBO9781139164023
Fay, C., M. Sirait, and A. Kusworo. 2000. Getting the Boundaries Right. Indonesia's Urgent Need to Redefine its Forest Estate. ICRAF Occasional Paper, Southeast Asia Policy Research Working Paper, No. 25. 18p.

Fay, C. and G. Michon. 2005. Redressing forestry hegemony. When a forestry regulatory framework is best replaced by an agrarian one. Forests, Trees and Livelihoods 15(2): 193-209. http://dx.doi.org/10.1080/14728028.2005.9752520

Feintrenie, L., S. Schwarze, and P. Levang. 2010. Are local people conservationists? Analysis of transition dynamics from agroforests to monoculture plantations in Indonesia. Ecology and Society 15(4): 37. [online] URL: http://www. ecologyandsociety.org/vol15/iss4/art37l.

Garcia, C. A., S. Bhagwat, J. Ghazoul, C. D. Nath, K. M. Nanaya, C. G. Kushalappa, Y. Raghuramulu, R. Nasi, and P. Vaast. 2010. Biodiversity conservation in agricultural landscapes: challenges and opportunities of coffee agroforests in the Western Ghats, India. Conservation Biology 24(2): 479-88. http://dx.doi.org/10.1111/j.1523-1739.2009.01386.x

Génin, D., and R. Simenel. 2011. Endogenous Berber forest management and the functional shaping of rural forests in southern Morocco: implications for shared forest management options. Human Ecology 39(3): 257-69. http://dx.doi. org/10.1007/s10745-011-9390-2

Genin, D., Y. Aumeeruddy-Thomas, G. Balent, and R. Nasi. 2013. The multiple dimensions of rural forests: lessons from a comparative analysis. Ecology and Society 18(1): 27. http:// dx.doi.org/10.5751/ES-05429-180127

Gibon, A., D. Sheeren, C. Monteil, S. Ladet, and G. Balent. 2010. Modelling and simulating mountain landscape reforestation using a socio-ecological framework. Landscape Ecology 25: 267-85. http://dx.doi.org/10.1007/s10980-009-9438-5

Kouplevatskaya, I. and G. Buttoud. 2008. Les trois visions de la forêt dans le débat sur le développement durable : planète, ressource et territoire. Revue Forestière Française 60: 307-22.

Lepais, O., J. Lavabre, M. Gonzalez, J. Willm, A. Cabanettes, and S. Gerber. 2006. Genetic diversity and genetic structure of oaks in two landscapes: impact of ecology, history and management (in French). Les Actes du BRG 6: 543-57.

Lescuyer, G. 2005. Formes d'action collective pour la gestion locale de la forêt camerounaise: organisations «modernes» ou institutions «traditionnelles»? VertigO 6(3). http://vertigo. revues. org/8029. http://dx.doi.org/10.4000/vertigo.8029

Lescuyer, G., S. Assembe Mvondo, J. N. Essoungou, V. Toison, J. F. Trébuchon, and N. Fauvet. 2012. Logging concessions and local livelihoods in Cameroon: from 
indifference to alliance? Ecology and Society 17(1): 7. http:// dx.doi.org/10.5751/ES-04507-170107

Linares, A. M. 2007. Forest planning and traditional knowledge in collective woodlands of Spain: The dehesa system. Forest Ecology and Management 249(1-2): 71-9. http://dx.doi.org/10.1016/j.foreco.2007.03.059

Macura, B., F. Zorondo-Rodríguez, M. Grau-Satorras, K. Demps, M. Laval, C. A. Garcia, and V. Reyes-García. 2011. Local community attitudes toward forests outside protected areas in India. Impact of legal awareness, trust, and participation. Ecology and Society 16(3): 10. http://dx.doi. org/10.5751/ES-04242-160310

Menon, A., C. Hinnewinkel, C. Garcia, S. Guillerme, N. Rai, and S. Krishnan. 2009. Competing Visions: Domestic Forests, Politics and Forest Policy in the Central Western Ghats of South India. Small-Scale Forestry 8: 515-27. http://dx.doi. org/10.1007/s11842-009-9096-0

Michon, G. 2005. Cultivating forests on farmlands. IRD/ CIFOR/ICRAF, Bogor, Indonesia.

Michon, G. 2011. Revisiting the resilience of chestnut forests in Corsica: from social-ecological systems theory to political ecology. Ecology and Society 16(2): 5. [online] URL: http:// www.ecologyandsociety.org/vol16/iss2/art5/.

Michon, G. and H. de Foresta. 1999. Agro-Forests: Incorporating a Forest Vision in Agroforestry. In L. E. Buck, J. Lassoie, and E. C. M. Fernandes, editors. Agroforestry in Sustainable Agricultural Systems. CRC Press LLC, Washington D. C., U.S.A. http://dx.doi.org/10.1201/9781420049473. $\underline{\operatorname{ch} 17}$

Michon, G., H. de Foresta, A. Kusworo, and P. Levang. 2000. The Damar Agro-Forests of Krui, Indonesia: Justice for Forest Farmers. Pages 159-203 in C. Zerner, editor. People, Plants and Justice. The Politics of Nature Conservation. Columbia University Press, New York, U.S.A.

Michon, G., H. de Foresta, P. Levang and F. Verdeaux. 2007. Domestic forests: a new paradigm for integrating local communities' forestry into tropical forest science. Ecology and Society 12(2): 1. [online] URL: http://www. ecologyandsociety. org/vol12/iss2/art1/

Michon, G., R. Nasi, and G. Balent. 2008. More than just small scale forest management. Pages 149-58 in G. Buttoud, editor. Small-scale rural forest use and management: global policies versus local knowledge. AgroParisTech-ENGREF, France.

Michon, G., B. Romagny, L. Auclair, and M. Deconchat. 2012. Forests as patrimonies? From theory to tangible processes at various scales. Ecology and Society 17(3): 7. http://dx.doi. org/10.5751/ES-04896-170307
Monteil, C., M. Deconchat, and G. Balent. 2005. Simple neural network reveals unexpected patterns of bird species richness in forest fragments. Landscape Ecology 20: 513-27. http://dx. doi.org/10.1007/s10980-004-3317-X

Nouaïm, R. 2005. L'arganier au Maroc, entre mythes et réalités. L'Harmattan, Paris, France.

Poissonnet, M., and G. Lescuyer. 2005. Aménagement forestier et participation: quelles leçons tirer des forêts communales du Cameroun?, VertigO 6(2). http://vertigo. revues. org/4290.

Rives, F., M. Antona, and S. Aubert. 2012. Social-ecological functions and vulnerability framework to analyze forest policy reforms. Ecology and Society 17(4): 21. http://dx.doi. org/10.5751/ES-05182-170421

San Miguel, A. 1994. La dehesa española. Origen, tipología, características y gestión, Fundación Conde del Valle de Salazar, Madrid, Spain. 96 pp.

Sauget, N. 1994. Of land, woods and men: farmers talk about the land, the evolution of woodland and the landscape. Landscape Issues 11: 52-58.

Simenel, R. 2011. Comment domestiquer une forêt sans les homes. Une ethnoécologie historique des forêts d'arganier du sud-ouest marocain. Techniques et Cultures 56: 224-47.

Simenel, R., G. Michon, L. Auclair, B. Romagny, Y. Thomas, and M. Guyon. 2009. L'argan: l'huile qui cache la forêt domestique De la valorisation du produit à la naturalisation de l'écosystème. Autrepart 50: 51-74. http://dx.doi. org/10.3917/autr.050.0051

Sourdril, A., E. Andrieu, A. Cabanettes, B. Elyakime, and S. Ladet. 2012. How to maintain domesticity of usages in small rural forests? Lessons from forest management continuity through a French case study. Ecology and Society 17(2): 6. http://dx.doi.org/10.5751/ES-04746-170206

Sunderlin, W., O. Ndoye, H. Bikié, N. Laporte, B. Mertens, and J. Pokam. 2000. Economic crisis, small-scale agriculture, and forest cover change in southern Cameroon. Environmental Conservation 27: 284-90. http://dx.doi.org/10.1017/ $\underline{\mathrm{S} 0376892900000321}$

Wiersum, K. F. 1997. Indigenous exploitation and management of tropical forest resources: an evolutionary continuum in forest-people interactions. Agriculture, Ecosystems \& Environment 63 (1): 1-16 http://dx.doi. org/10.1016/S0167-8809(96)01124-3

Wunder, S. 2001. Poverty Alleviation and Tropical ForestsWhat Scope for Synergies? World Development 29: 1817-33. http://dx.doi.org/10.1016/S0305-750X(01)00070-5 